\title{
New Caffeic Acid Esters from Plazia daphnoides
}

Maritza Hoeneisen ${ }^{\mathrm{a}, *}$, Julio Alarcón ${ }^{\mathrm{b}}$, Pedro Aqueveque ${ }^{\mathrm{a}}$, Magalis Bittnera Jose Becerra $^{a}$, Mario Silva ${ }^{\mathrm{a}}$, and Jasmin Jakupovic ${ }^{\mathrm{c}}$

a Laboratorio Quimica Productos Naturales, Dpto. de Botánica, Universidad de Concepción, Concepción, Chile. Fax: +56-41-221569.E-mail: mhoeneis@udec.cl

b Depto. Ciencias Básicas, Facultad de Ciencias, Universidad del Bío Bío, Chillán, Chile

c Institute for Organic Chemistry, Technical University of Berlin, D-10623 Berlin 12, Germany

* Author for correspondence and reprint request

Z. Naturforsch. 58c, 39-41 (2003); received July 17/August 16, 2002

Two new 3,4 dihydroxycinnamic acid esters have been isolated from Plazia daphnoides. The structures were elucidated by NMR spectroscopy.

Key words: Plazia daphnoides, Asteraceae, 3,4 Dihydroxycinnamic Acid Esters

\section{Introduction}

In the course of continuing studies on plants of the tribe Mutisieae (Asteraceae), widely distributed in Chile, with 30 genus and 203 species (Marticorena and Quezada; 1995; Cabrera; 1977) from this tribe several characteristic groups of natural products have been isolated. Some of them in part are typical for the subtribe Gochnatiinae, where the Plazia genus has been placed ( Zdero et al., 1988a). Previously, the oil of Plazia daphnoides was destillated and analyzed isolating phenols and volatile fatty acids. Also the aerial parts where examined isolating kolavenol, the flavanoids naringerin, sakuranetin, isokuranetin, acacetin and genkwanin, lupeyl acetate, $\alpha$ - and $\gamma$-curcumene, (-)-9-acetoxycapric acid, the 5-methyl coumarins lycoserone and its 1 '-epimer, cyclolycoserone and its dehydroderivative (Fester et al., 1958; Zdero et al., 1988b).

In a continuation of our investigation of Chilean Mutisieae (Galvez et al., 1986; Hoeneisen and Becker, 1986; Hoeneisen and Silva, 1986; Maldonado et al., 1988; Hoeneisen et al., 1993, 1997, 1999, 2000) here we report the isolation and structure elucidation of two new compounds: isobutyl-3,4dihydroxycinnamate (1) and 2-methyl-2-butenyl3,4-dihydroxycinnamate (2) from the aerial parts of Plazia daphnoides, a species which has not been subjected to a thorough phytochemical analysis.

\section{Materials and Methods}

General experimental procedures

${ }^{1} \mathrm{H}-\mathrm{NMR}$ were recorder at $400 \mathrm{MHz}$ and ${ }^{13} \mathrm{C}$ NMR at $100 \mathrm{MHz}$ on Bruker spectrometers, chemical shifts $(\mathrm{ppm})$ are related to $\left(\mathrm{CH}_{3}\right)_{4} \mathrm{Si}$ as internal reference.

\section{Plant material}

Aerial parts from $P$. daphnoides were collected in Tiliviri (3210 m.s.m.), Prov. Parinacota (I Region, Chile). Voucher specimen (Matthei and Rodriguez 248) can be found at the botanical collection of the herbarium (CONC), Departamento de Botánica, Facultad de Ciencias Naturales y Oceanograficas, Universidad de Concepción, Concepción, Chile.

Isolation and purification of isobutyl-3,4-dihydroxycinnamate (1) and 2-methyl-2-butenyl-3,4-dihydroxycinnamate (2)

Dried plant material $(3.0 \mathrm{~kg})$ was crushed and percolated at room temperature with $\mathrm{MeOH}$, which was evaporated under vaccuum, the residue (409 g) was dissolved in $\mathrm{H}_{2} \mathrm{O}$. The solution was partitioned with n-hexane $(3 \times 500 \mathrm{ml}), \mathrm{CH}_{2} \mathrm{Cl}_{2}$ $(3 \times 500 \mathrm{ml})$ and EtOAc $(3 \times 500 \mathrm{ml})$. The $\mathrm{CH}_{2} \mathrm{Cl}_{2}$, evaporated to dryness, afforded $230,9 \mathrm{~g}$ of $\mathrm{CH}_{2} \mathrm{Cl}_{2}$ extract. This was fractionated by flash chromatography eluting with n-hexane with increasing 10\% volume amounts of EtOAc and finally 100\% 


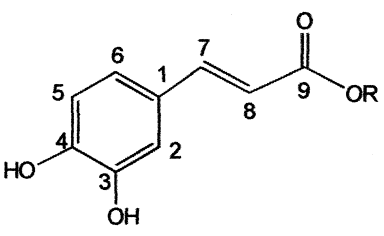

1<smiles>CCC(C)C</smiles>

2<smiles>CCC=C(C)C</smiles>

Fig. 1. Caffeic acid ester isolated from P. daphnoides.

\begin{tabular}{|c|c|c|c|c|}
\hline \multirow[b]{2}{*}{ Carbon } & \multicolumn{2}{|c|}{ Compound $\mathbf{1}$} & \multicolumn{2}{|c|}{ Compound 2} \\
\hline & $\delta \mathrm{H}$ & $\delta \mathrm{C}$ & $\delta \mathrm{H}$ & $\delta \mathrm{C}$ \\
\hline 1 & & 127.0 & & \\
\hline 2 & $7.09 \mathrm{~d}(2)$ & 115.4 & $7.08 \mathrm{~d}(2)$ & \\
\hline 3 & & 144.1 & & \\
\hline 4 & & 146.8 & & \\
\hline 5 & 6.95 dd $(2,6)$ & 114.3 & $6.93 \mathrm{dd}(2,8)$ & \\
\hline 6 & $6.87 \mathrm{~d}(8)$ & 122.5 & $6.86 \mathrm{~d}(8)$ & \\
\hline 7 & $7.56 \mathrm{~d}(16)$ & 145.6 & 7.56 d (16) & 145.7 \\
\hline 8 & $6.24 \mathrm{~d}(16)$ & 114.9 & $6.23 \mathrm{~d}(16)$ & \\
\hline 9 & & 168.8 & & 168.7 \\
\hline $1^{\prime}$ & 3.98 d (7) & 71.1 & 4.70 brd (7) & 61.9 \\
\hline $2^{\prime}$ & 2.00 tqq $(7,7,7)$ & 27.7 & 5.40 bst (7) & 118.2 \\
\hline $3^{\prime}$ & $0.97 \mathrm{~d}(7)$ & 19.1 & 1.76 brs & 139.6 \\
\hline $4^{\prime}$ & & 19.1 & 1.72 brs & 27.7 \\
\hline $5^{\prime}$ & & & & 18.0 \\
\hline
\end{tabular}

Table I. ${ }^{1} \mathrm{H}$ and ${ }^{13} \mathrm{C}$ NMR data for compounds isolated from Plazia daphnoides. Coupling constants $\mathrm{Hz}$ in parenthesis.

$\mathrm{MeOH}$. The residue from the fraction eluted with $20 \%$ EtOAc in $\mathrm{CH}_{2} \mathrm{Cl}_{2}(14 \mathrm{~g})$ was chromatographed over Sephadex LH20 and afforded isobutyl-3,4-dihydroxycinnamate (1) and 2-methyl-2butenyl-3,4-dihydroxycinnamate (2) (Fig. 1) by eluation with acetone. They were separated by preparative TLC using $\mathrm{CHCl}_{3}-\mathrm{MeOH}(4: 1 \mathrm{v} / \mathrm{v})$.

\section{Results and Discussion}

The ${ }^{1} \mathrm{H}$ NMR spectrum of $\mathbf{1}$ exhibited signals for three aromatic protons in a 2,5,6 substitution pattern, two broad hydroxyl singlets ( $\delta 5.65$ and $\delta 6.05)$, which together with two protons of a trans-doble bond $(\mathrm{J}=16 \mathrm{~Hz})$, indicated the presence of a 3,4-dihydroxy-trans-cinnamate (caffeate) moiety. Further signal for a deshielding indicated the presence of a small alkyl chain. The carbon spectrum (Table I) confirmed the presence of a dihydroxy cinnamate derivative with resonances attributable to a carbonyl group ( $\delta$ 168.8), two deshielded oxygen bearing quaternary carbon. The structure of compound $\mathbf{2}$ was deduced from the NMR data, which are similar to those of $\mathbf{1}$, but showing a different signal for the methyl groups at the alkyl chain.

\section{Acknowledgements}

The authors thank the Dirección de Investigación project $\mathrm{N}^{\circ} 210.111 .027-1$ Universidad de Concepción. 
Cabrera, A. (1977), Mutisieae-systematic review. In: The Biology and Chemistry of the Compositae (Heywood,V. H., Harborne, J. B. and Turner, B. L., eds.). Academic Press, London, pp. 1039-1066.

Fester G. A., Martinuzzi E. A., Retamar J. and A., Ricciardi A. I. A. (1958), Essential oils from Argentine plants. Bol. Acad. Nac. Cienc. 40, 189-208.

Galvez M., Hoeneisen M., Silva M. and Watson W. H. (1986), Germacra-1 (10), 4-dien-cis-6,12-olide from Gochnatia foliolosa var. foliolosa. Bol. Soc. Chil. Quim. 31 (1), 3-5.

Hoeneisen M. and Becker H. (1986), New Germacranolide flora Gochnatia foliolosa var. foliolosa. Lloydia 49, 360-361.

Hoeneisen M., Hernandez V., Becerra J., Bittner M., Silva M. and Jakupovic J. ( 1999), Constituents from Nassauvia pygmaea and N. Magellanica. Phytochemistry 52, 1667-1669.

Hoeneisen M., Rojas A., Bittner M., Becerra J., Silva M. and Jakupovic J. (2000), Constituents of Chuquiraga atacamensis and C. ulicina. Bol. Soc. Chil. Quím. 45, 49-52.

Hoeneisen M. and Silva M. (1986), Química y actividad biológica de algunas Compositae chilenas. Rev. Latin Amer. Quim. 17, 19-24.
Hoeneisen, M., Silva M., Garrido M. and Jakupovic J. (1997), Constituents from Nassauvia pygmaea and $N$. Magellanica. Bol. Soc. Chil. Quím. 42, 203-205.

Hoeneisen, M. Silva M., Jakupovic J., Papastergion F. and Peter M. G. (1993), Flavanones of Lophopappus tarapacanus and triterpenoids of Pachylaena atriplicifolia. Phytochemistry 34, 1653.

Hoeneisen M., Silva M., Jakupovic J. and Steglich W. (1997), Isocedrene derivatives and other constituents of Trixis cacaloides. Bol. Soc. Chil. Quím. 42, 307-310.

Hoeneisen M., Silva M. and Jakupovic J. (1997), Coumarins from Nassauvia cumingii. Phytochemistry 46, $1393-1395$.

Maldonado Z., Hoeneisen M. and Silva M. (1988), New dithiophene flora Aphyllocladus denticulatus. Phytochemistry 27, 2993-2994.

Marticorena, C. and Quezada, M. (1995), Catalog of the vascular flora of Chile. Gayana Botánica 42, 5-155.

Zdero, C., Bohlmann, F. and Niemeyer, H. M. (1988a), 5-methylcoumarin derivatives from Aphyllocladus denticulatus. Phytochemistry 27, 1821.

Zdero C., Bohlmann F. and Niemayer H. (1988b), Diterpenes and 5-methyl coumarin derivatives from Gypothamnium pinifolium and Plazia daphnoides. Phytochemistry 27, 2953-2959. 